Article

\title{
Investigation of Dynamic Loads in Wind Turbine Drive Trains Due to Grid and Power Converter Faults
}

\author{
Julian Röder*(D), Georg Jacobs $\mathbb{D}$, Tobias Duda, Dennis Bosse and Fabian Herzog
}

Citation: Röder, J.; Jacobs, G.; Duda, T.; Bosse, D.; Herzog, F. Investigation of Dynamic Loads in Wind Turbine Drive Trains Due to Grid and Power Converter Faults. Energies 2021, 14 , 8542. https://doi.org/10.3390/ en14248542

Academic Editors: Carsten Ebert and Davide Astolfi

Received: 29 November 2021 Accepted: 15 December 2021 Published: 17 December 2021

Publisher's Note: MDPI stays neutral with regard to jurisdictional claims in published maps and institutional affiliations.

Copyright: (c) 2021 by the authors. Licensee MDPI, Basel, Switzerland. This article is an open access article distributed under the terms and conditions of the Creative Commons Attribution (CC BY) license (https:// creativecommons.org/licenses/by/ $4.0 /)$.
Center for Wind Power Drives (CWD), RWTH Aachen University, 52062 Aachen, Germany; georg.jacobs@cwd.rwth-aachen.de (G.J.); tobias.duda@cwd.rwth-aachen.de (T.D.); dennis.bosse@cwd.rwth-aachen.de (D.B.); fabian.herzog@cwd.rwth-aachen.de (F.H.)

* Correspondence: Julian.roeder@cwd.rwth-aachen.de

\begin{abstract}
Electrical faults can lead to transient and dynamic excitations of the electromagnetic generator torque in wind turbines. The fast changes in the generator torque lead to load oscillations and rapid changes in the speed of rotation. The combination of dynamic load reversals and changing rotational speeds can be detrimental to gearbox components. This paper shows, via simulation, that the smearing risk increases due to the electrical faults for cylindrical roller bearings on the high speed shaft of a wind turbine research nacelle. A grid fault was examined for the research nacelle with a doubly fed induction generator concept. Furthermore, a converter fault was analyzed for the full size converter concept. Both wind turbine grid connection concepts used the same mechanical drive train. Thus, the mechanical component loading was comparable. During the grid fault, the risk of smearing increased momentarily by a maximum of around 1.8 times. During the converter fault, the risk of smearing increased by around 4.9 times. Subsequently, electrical faults increased the risk of damage to the wind turbine gearbox bearings, especially on the high speed stage.
\end{abstract}

Keywords: wind turbine; drive train; dynamic loads; grid fault; converter fault

\section{Motivation}

Wind energy is taking an increasing share in the energy supply of the future, while costs for wind turbines (WTs) steadily decline due to technology improvements. The operational costs of WTs can be reduced by increasing its reliability [1]. Reliability improvements can be achieved by explicitly considering special load scenarios that are currently not considered sufficiently in the WT development. Dependent on the WT concept, grid faults can lead to dynamic electromagnetic torque excitations with amplitudes significantly higher than the rated torque [2]. Faults in the power electronics [3], e.g., the converter, can also induce significant torque excitations [4,5].

However, gearbox damages are the main contributor to WT downtime. Gearbox damages occur mainly on bearings and gears of the high speed stage (HSS). Around 48 per cent of the gearbox damages are attributed to the HSS bearings [6,7].

Therefore, an investigation of electrical faults and their influence on an increase in the risk of damages to the WT gearbox components is conducted at the CWD in the project DynaGET. As generator torque excitations have the highest influence on the loading of the HSS gearbox components [5], the HSS bearings are the main focus in this research.

\section{Approach}

In order to quantify the loads due to grid faults, fault ride through (FRT) experiments can be carried out in the field or on test benches (see Figure 1). Furthermore, validated multi-body simulation (MBS) models can be used to simulate grid faults and, e.g., shortcircuit converter faults that cannot economically be tested on test benches. 


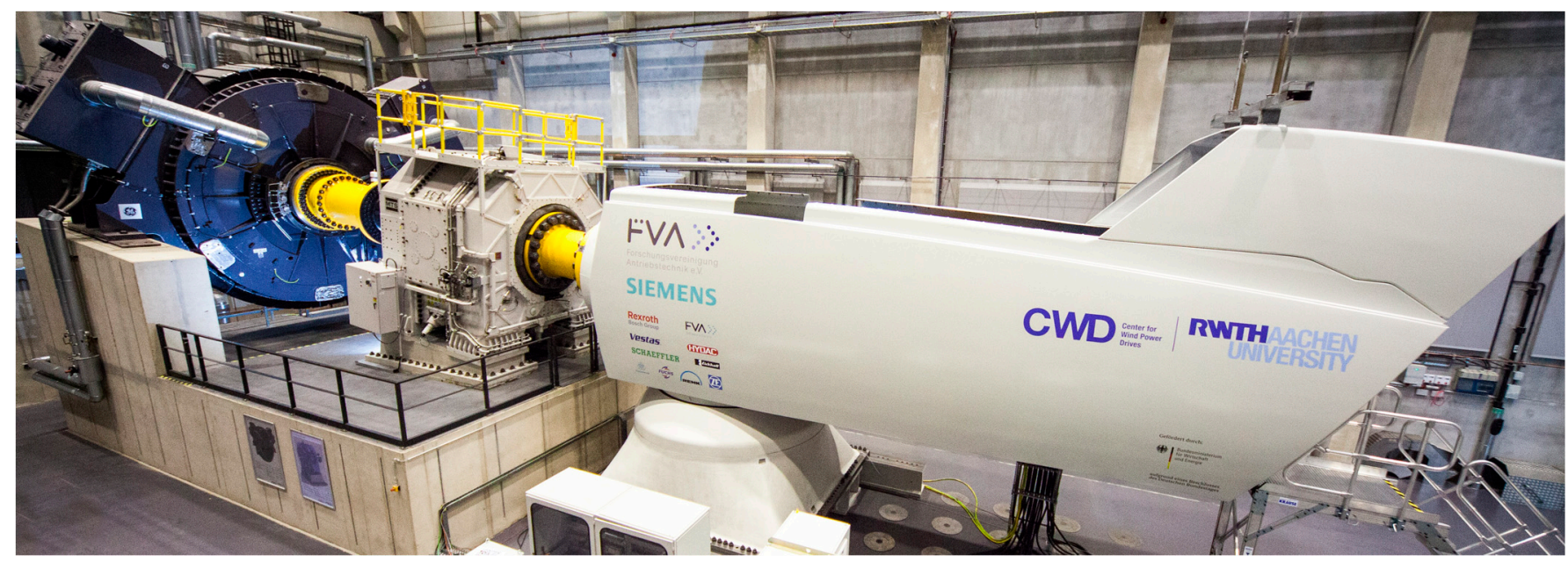

Figure 1. Drive train on CWD's test bench.

For a simulative quantification of the risk of damage to the drive train components during electrical faults, the drive train loads and kinematics have to be calculated and evaluated via damage criteria. For the load calculation, a model of a WT research nacelle, described in Section 3, is used. Two different grid connection concepts were investigated, while the mechanics of the drive train were not changed. Therefore, the influence of the electrical faults on the mechanical loading can be compared for the different concepts.

In the doubly fed induction generator (DFIG) concept (see Figure 2), the WT is only partially decoupled from the grid via the partial scale converter (PSC). Due to the direct connection of the generator's stator, grid faults affect the electromagnetic field in the stator significantly, which leads to a transient torque excitation [2]. A fault ride through scenario, corresponding to the current European grid codes, is investigated. The resulting torque and drive train loads are discussed in Section 4.

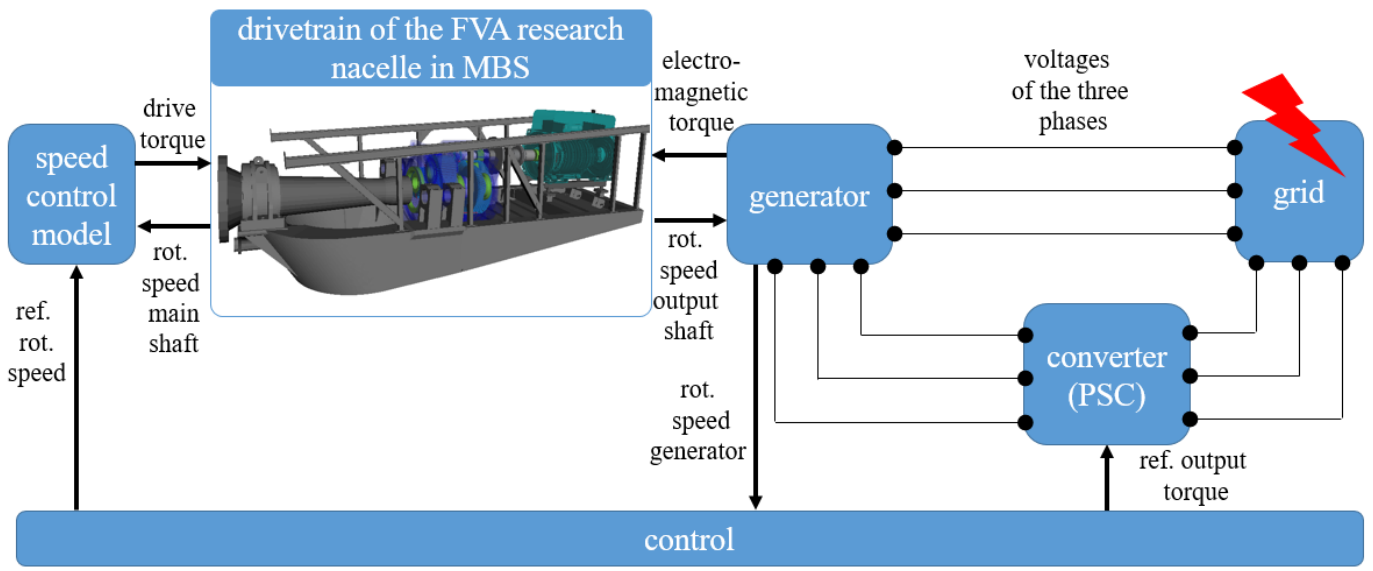

Figure 2. Schematic of the DFIG concept research nacelle model.

In the full-scale power converter (FSC) concept, the WT is completely decoupled from the grid via the converter and countermeasures, e.g., brake choppers (see Figure 3). Therefore, in general, grid faults do not induce significant excitations for the FSC concept. Hence, a converter fault is analyzed (see Figure 3). The fault, its influence on the generator currents, as well as the resulting drive train torque load, is discussed in a previous publication [8].

In order to quantify the risk of damage to the gearbox bearings a smearing criterion [9] is evaluated using the MBS results as an input. 


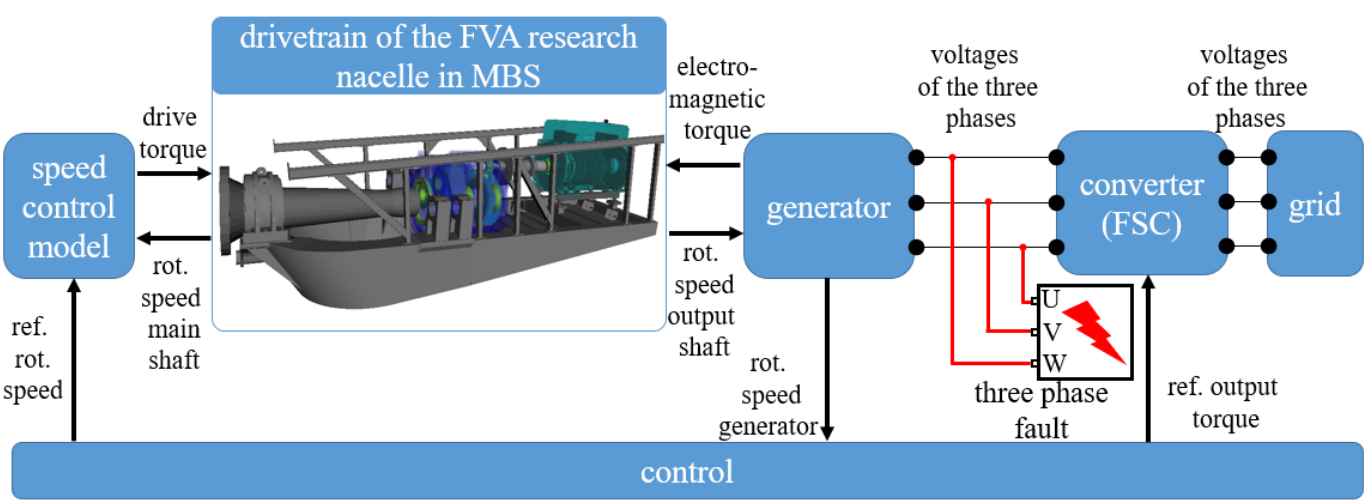

Figure 3. Schematic of the FSC concept research nacelle model.

\section{Models}

The drive train model (MBS) is connected with analytical models for the electrical system (see Figures 2 and 3) via a co-simulation [10-12]. The drive torque of the test bench motor is calculated using a speed control model and implemented as an excitation to the MBS model (see Figures 2-4). The faults occur at a HSS rotational speed of $1100 \mathrm{rpm}$. Besides a rotor weight emulation, the non-torque loads resulting from the wind are disregarded in this paper for an independent evaluation of the loading due to the electrical faults.

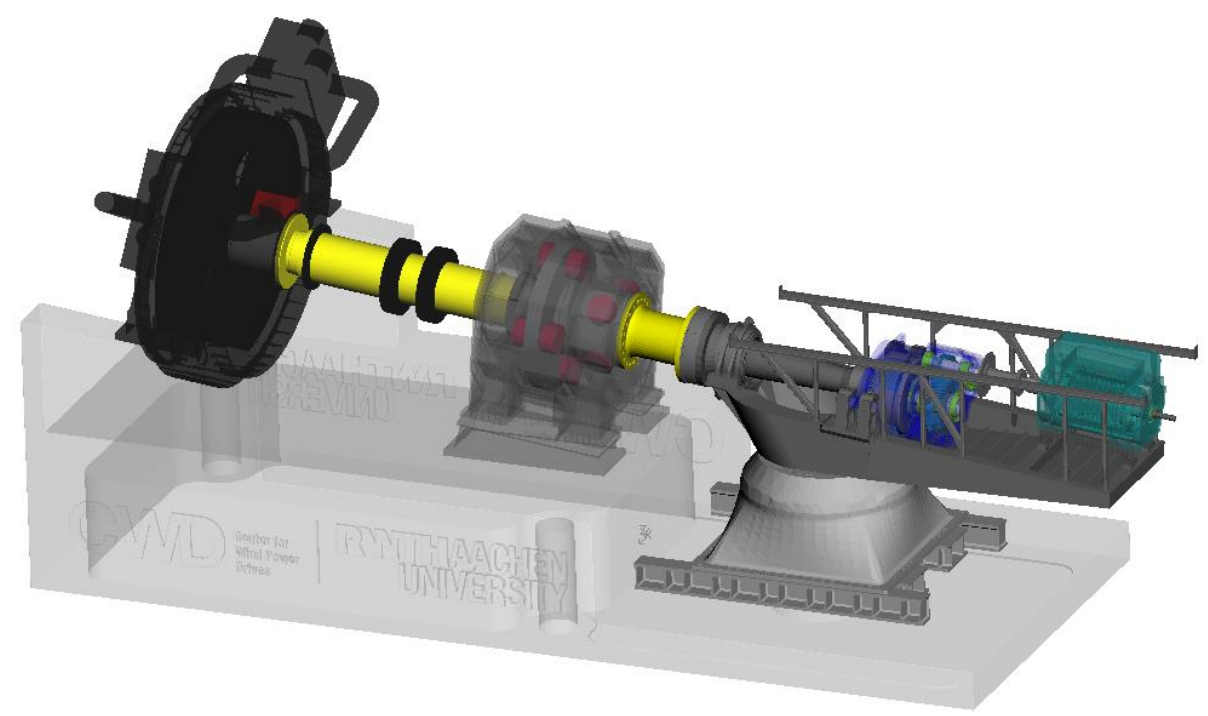

Figure 4. Drive train model including CWD's test bench (MBS).

For both concepts, the same generator with slight adaptations was used. Specific parameters of the generator (see Table 1) are provided by the manufacturer. The generator was implemented as an analytical model based on the fundamental electromagnetic waves. This fidelity is sufficient for calculating damage relevant loads within the drive train [10].

The model of the grid mainly emulates the inductances [10]. Both the PSC and the FSC are modelled according to the IEC 61400 and other state-of-the-art guidelines [13].

The drive train model also includes the CWD test bench (Figure 4) [10-12]. This model was chosen for the investigation in this paper because its validity was shown using data from extensive experiments with regard to IEC 61400 and via a converter fault test in idling mode [4,5,10-12].

The investigated gearbox (see Figure 5) has a gear ratio of around 63 and consists of a planetary stage as well as two helical gear stages. The gear wheel contact is implemented via a gear pair force element and backlash is included. The bearings are modelled as springdamper elements with input functions for the stiffness and damping [10-12]. A detailed 
model is implemented for the rotor side cylindrical roller bearing [14] (see Figure 5) in order to calculate the Hertzian contact pressure and the kinematics of each roller for the evaluation of a smearing criterion.

Table 1. Parameters of the generator.

\begin{tabular}{cc}
\hline Parameter & Value \\
\hline Type & Asynchronous \\
Pole pair number & 3 \\
Power & $3 \mathrm{MVA}$ \\
Voltage (rated) & $720 \mathrm{~V}$ \\
Current (rated) & $2564 \mathrm{~A}$ \\
Torque (rated) & $24.7 \mathrm{kNm}$ \\
Speed of rot. HSS (rated) & $1100 \mathrm{rpm}$ \\
\hline
\end{tabular}

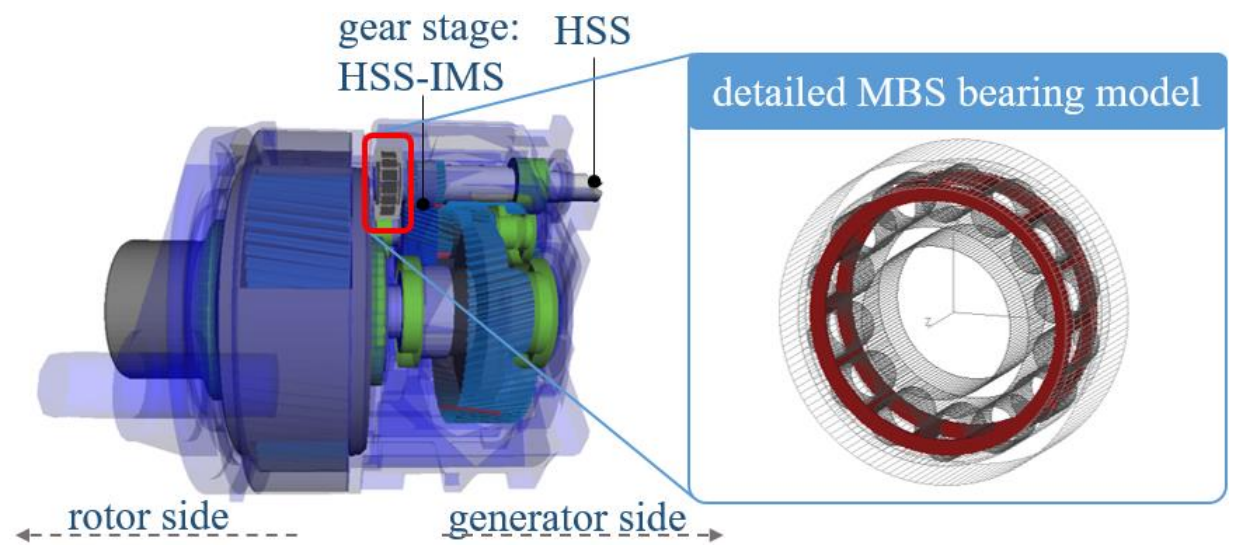

Figure 5. Gearbox and detailed bearing model (MBS).

The smearing criterion [9] derives the power $\mathrm{P}$ on Area $\mathrm{A}$ and consists of the friction coefficient $\mu$ the difference in circumferential velocity of the contact partners $\mathrm{u}_{1}(\mathrm{t})-\mathrm{u}_{2}(\mathrm{t})$ and the maximum Hertzian contact pressure $p_{\max }(t)$ :

$$
\left(\frac{\mathrm{P}}{\mathrm{A}}\right)_{\max }=\max \left(0.5 \cdot \mu \cdot \mathrm{p}_{\max }(\mathrm{t}) \cdot\left(\mathrm{u}_{1}(\mathrm{t})-\mathrm{u}_{2}(\mathrm{t})\right)\right.
$$

\section{Results}

The first load case discussed in this paper's simulative investigation is the grid fault for the DFIG concept WT (see Figure 2). The three-phase line-to-line voltages $\left(\mathrm{U}_{\mathrm{U}-\mathrm{V}}, \mathrm{U}_{\mathrm{V}-\mathrm{W}}\right.$, $\left.\mathrm{U}_{\mathrm{W}-\mathrm{U}}\right)$ for the grid fault are shown in Figure 6 (left). In Figure 6 (right), the resulting electromagnetic, mechanical HSS and drive torque is shown with regard to the gearbox ratio and normalized by the nominal torque. The grid fault starts at $t=10 \mathrm{~s}$. Over a period of $3 \mathrm{~ms}$, the voltages decreased linearly to 5 per cent of the nominal value. This voltage level was kept for $97 \mathrm{~ms}$. As a result, the generator torque shortly increased to 1.8 times the rated torque before it rapidly decreased to zero. The control detected the fault and the sharp decrease of the generator torque. Therefore, the drive torque, applied via the test bench motor, also started decreasing. The speed of rotation of the HSS increased (see Figure 7, left) because of the slower decrease in drive torque than in the electromagnetic generator torque, which was a result of the drive's high inertia. The mechanical HSS torque oscillated shortly after the fault was triggered. It reached 1.12 times nominal value before it decreased to a minimum of around 68 per cent over a period of $97 \mathrm{~ms}$. Then, the fault was cleared and the voltages increased to the nominal value again linearly in $3 \mathrm{~ms}$. As a result, the electromagnetic torque increased rapidly. It shortly reached 2.5 times nominal value before it declined to the rated value again. Therefore, the speed of rotation of the 
HSS decreased significantly and the mechanical HSS torque increased with a sharp peak. The control also detected the restored normal grid operation and started increasing the drive torque. Subsequently, the mechanical HSS torque steadily increased and reached its nominal value again at $\mathrm{t}=11.5 \mathrm{~s}$.
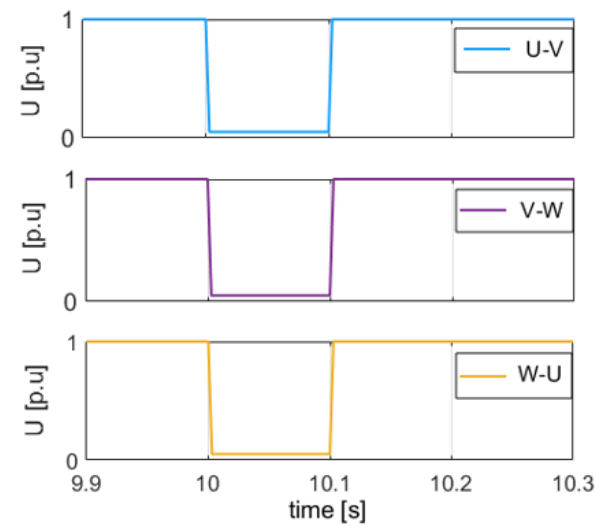

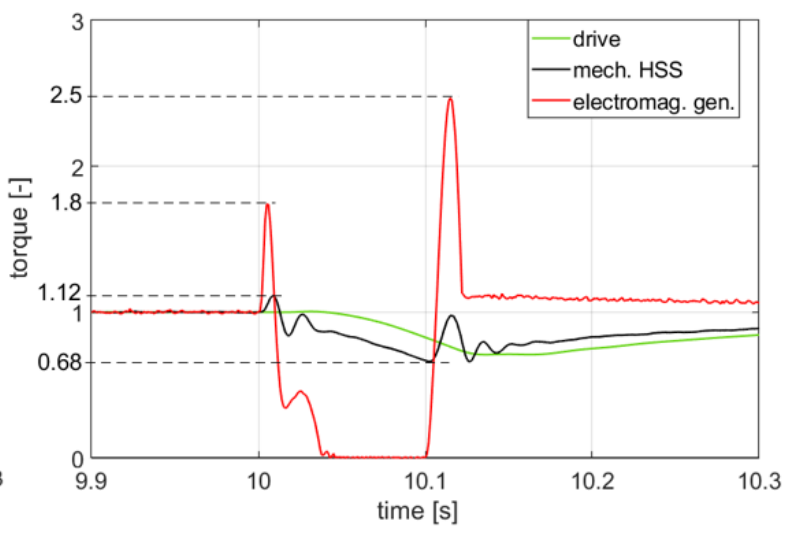

Figure 6. Voltages during the grid fault (left), corresponding electromagnetic, mechanical HSS and drive torque for the DFIG concept, normalized by the gearbox ratio and the nominal torque (right).
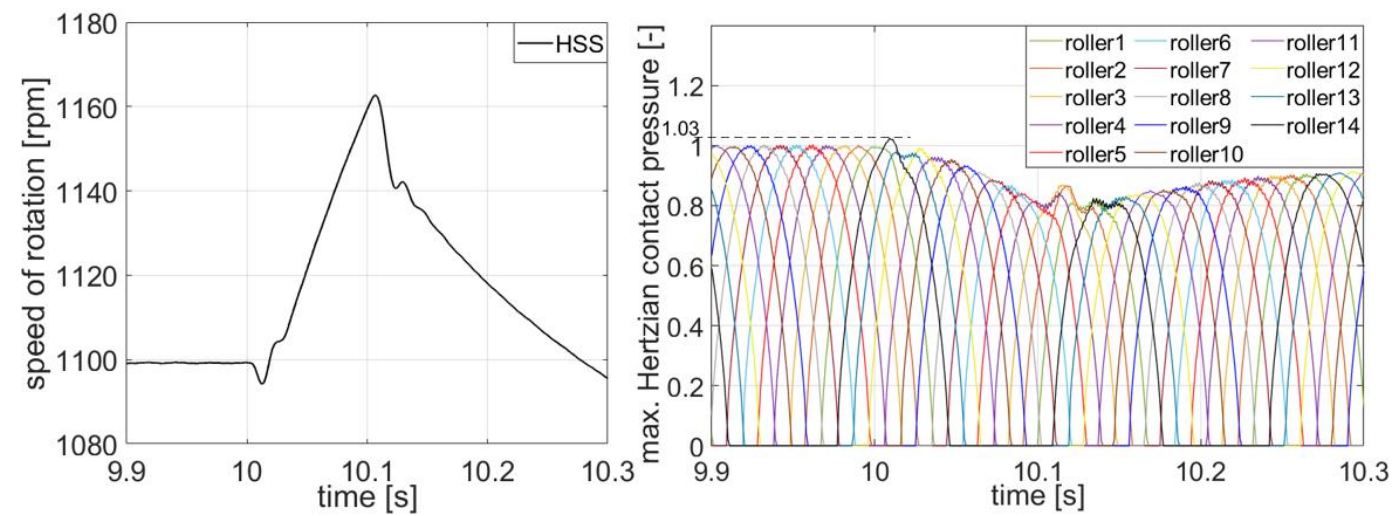

Figure 7. HSS speed of rot. (left), $p_{\max }(t)$ between each roller and the inner ring normalized by the nominal value (right), grid fault, DFIG concept.

The dynamic torque excitations were transferred to the loading of the drive train components. In Figure 7 (right), $p_{\max }(t)$ between the rollers and the inner ring of the cylindrical roller bearing is shown exemplarily. After the grid fault occurred, $p_{\max }(t)$ increased initially by a maximum of around 3 per cent for one roller (see Figure 7, right). Afterwards, the gearbox bracing decreased. Thus, $\mathrm{p}_{\max }(\mathrm{t})$ also sank to a minimum of around 80 per cent over a period of $97 \mathrm{~ms}$. As the fault was cleared at $t=10.1 \mathrm{~s}, p_{\max }(t)$ peaks for the rollers in contact before it steadily increased due to the increasing drive torque and bracing of the gearbox. At $t=11.5 \mathrm{~s}$, the turbine was at normal operating mode and $\mathrm{p}_{\max }(\mathrm{t})$ reached its nominal value again.

In Figure 8, the normalized smearing criterion is shown for roller 1, which shows the most critical behavior during the grid fault. The smearing criterion was normalized to its value at nominal torque load. After the fault occurred at second 10, the bracing of the gearbox decreased. Therefore, $p_{\max }(t)$ decreased (see Figure 7 , right). The speed of rotation increased rapidly (see Figure 7, left). This led to an increase in the maximum difference of circumferential velocity (see Figure 8, blue line, max. 1.72 times nominal value) due to an increase in slip. As the fault was cleared at $t=10.1 \mathrm{~s}$, the bracing of the gearbox increased rapidly. As the roller entered the load zone again, the slip and, therefore, the difference in circumferential velocity, was still high (1.42 times nominal value), while $\mathrm{p}_{\max }(\mathrm{t})$ increased to around 28 per cent of the nominal value. This momentarily led to an increase in the 
smearing criterion of around 1.8 times in comparison to the nominal value during nominal torque load. After the gearbox was braced again, the speed of rotation stabilized and the maximum difference in circumferential velocity declined to nominal value. Accordingly, the smearing criterion declined to the nominal value again.

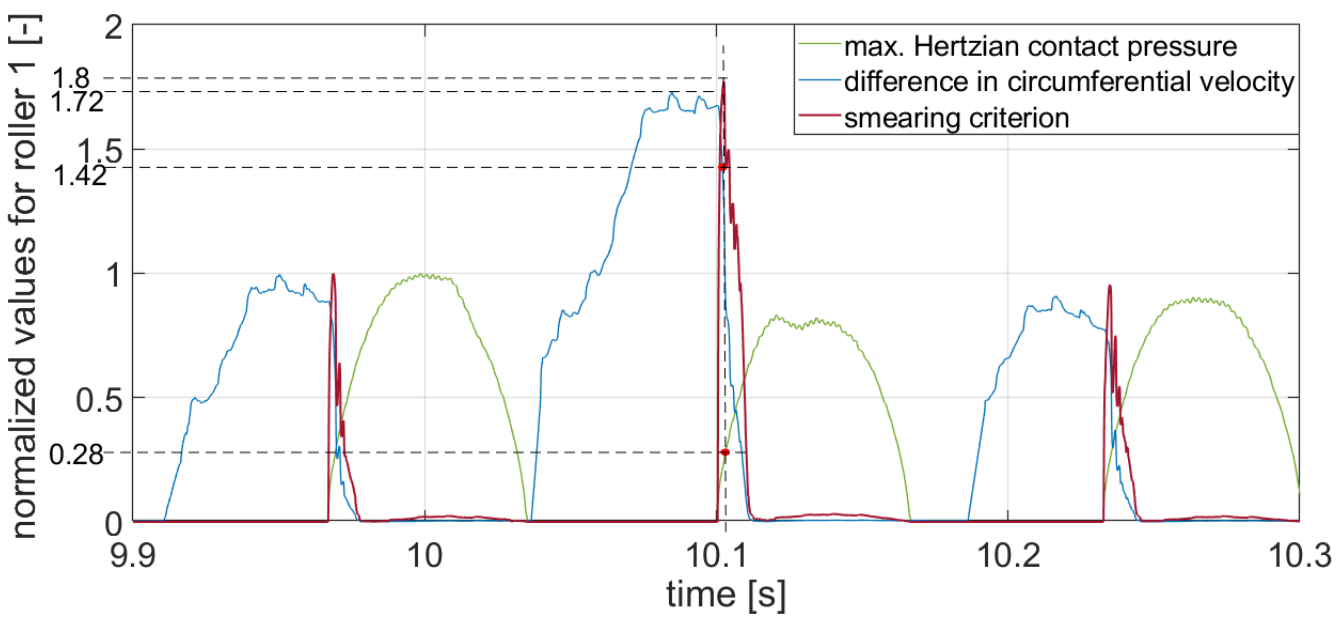

Figure 8. Smearing criterion, $\mathrm{p}_{\max }(\mathrm{t})$ and $\mathrm{u}_{1}(\mathrm{t})-\mathrm{u}_{2}(\mathrm{t})$ for roller 1 , normalized by the nominal values, grid fault, DFIG concept.

The second load case was the converter fault in the WT with FSC concept (see Figure 3). The resulting highly dynamic torque loading of the WT is discussed in detail in a previous publication [8]. For reference, the speed of rotation, the drive train torque load and $p_{\max }(t)$ of the rollers of the HSS cylindrical roller bearing is shown in Figure 9. The dynamic torque excitation led to an oscillation in the HSS speed of rotation. After a short spike, the contact pressure oscillated and decreased rapidly due to the decreasing bracing of the drive train.
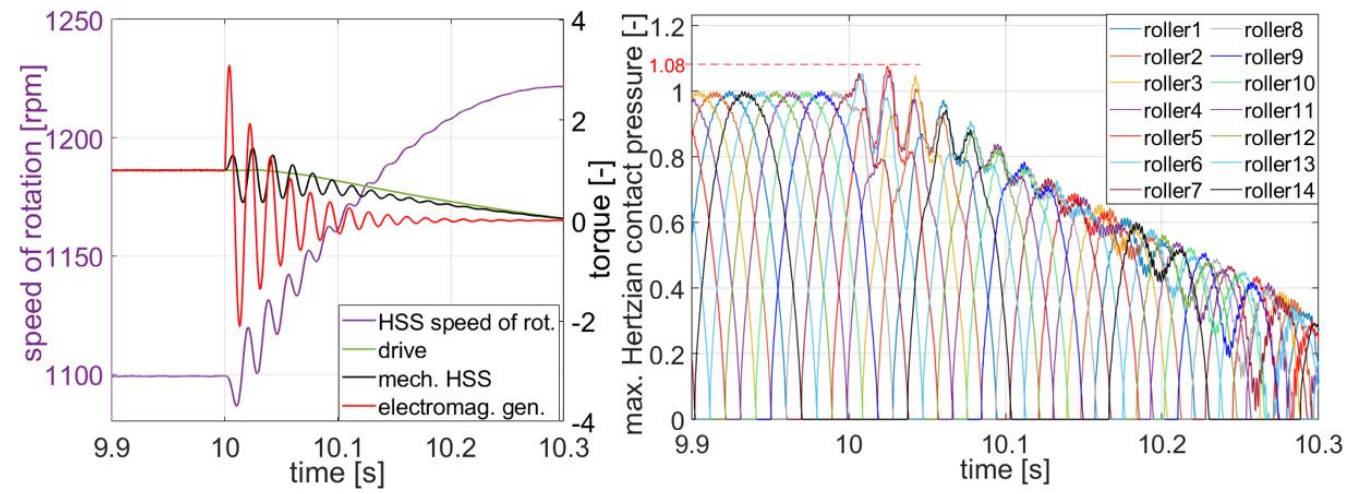

Figure 9. HSS speed of rot., electromagnetic, mechanical HSS and drive torque normalized by the gearbox ratio and the nominal torque (left), $p_{\max }(\mathrm{t})$ for each roller and the inner ring normalized by the nominal value (right), converter fault, FSC concept.

In Figure 10, the normalized smearing criterion for roller 9, which shows the most critical behavior, is depicted. The smearing criterion was normalized to its value at nominal torque load. As the fault was triggered at second ten, the loading and the speed of rotation started to oscillate significantly (see Figure 9). As a result of the oscillating speed of rotation, $\mathrm{u}_{1}(\mathrm{t})-\mathrm{u}_{2}(\mathrm{t})$ of roller 9 (see Figure 10, blue line) increased by a maximum of around 5 times compared to the nominal value. As the roller approached the load zone again, $\mathrm{u}_{1}(\mathrm{t})-\mathrm{u}_{2}(\mathrm{t})$ was still elevated (around 3.2 times nominal value) while $p_{\max }(t)$ already reached around 47 per cent of its nominal value. As a result, the smearing criterion increased by a maximum of 4.93 times compared to the nominal value momentarily. Afterwards, the bracing of the gearbox and, therefore, $p_{\max }(t)$ decreased. Subsequently, the smearing criterion also approached lower levels. 


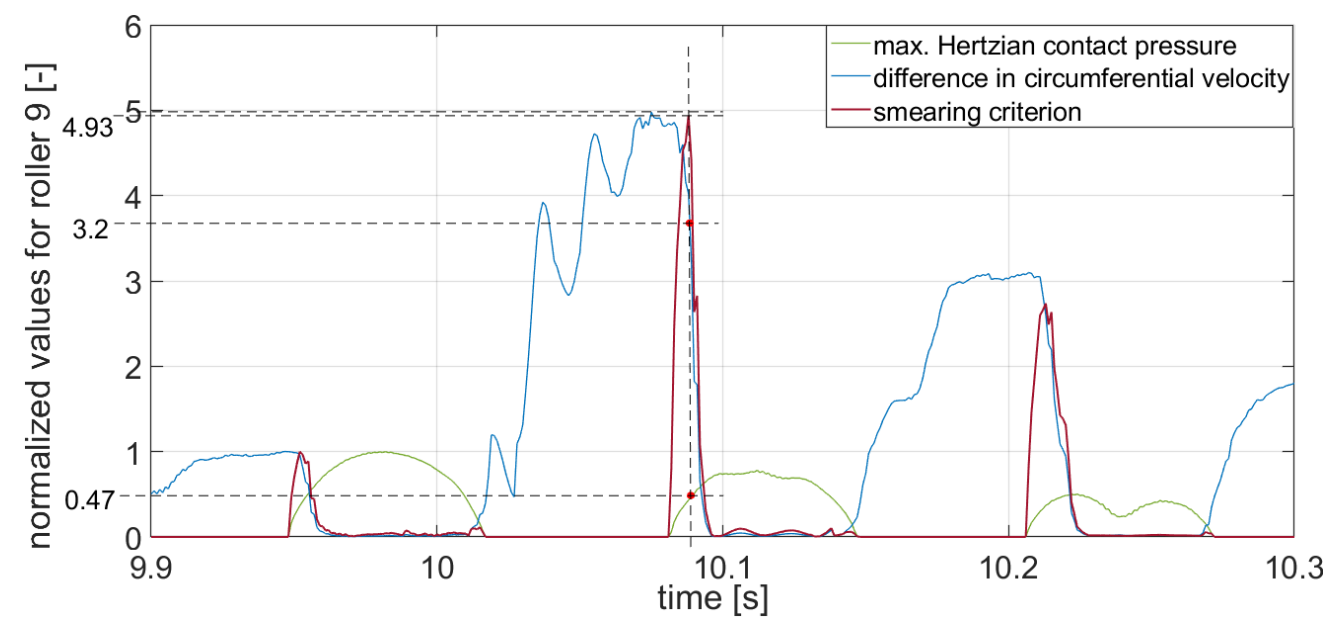

Figure 10. Smearing criterion, $p_{\max }(t)$ and $u_{1}(t)-u_{2}(t)$ for roller 9 , normalized by the nominal values, converter fault, FSC concept.

\section{Conclusions}

The shown electrical faults led to transient dynamic torque excitations. The simulative investigation shows that especially the components on the HSS of the gearbox show load oscillations in combination with rapid changes in the speed of rotation due to the torque excitations, which can be detrimental for the gearbox components. The shown grid fault with the DFIG concept increases the risk of smearing momentarily by around 1.8 times for the HSS cylindrical roller bearing. The short-circuit converter fault in the FSC concept momentarily leads to an increase in the smearing risk of around 4.93 times. Thus, both electrical faults increase the risk of damage to the depicted HSS bearing.

\section{Outlook}

The project DynaGET at the CWD will further examine the risk of damage to the components of WT drive trains during electrical faults via extensive experiments and simulations. The measurements of the drive train at CWD's testing facility deliver new insights regarding the torque load as well as the loading of the bearings and gears. In addition, tests and simulations with an emulation of the WT rotor inertia will deliver results that are closer to the rotor dynamics of the WT in the field compared to the test bench with speed control. Additionally, the simulation models will be further validated. The evaluation of the risk of smearing will be done for all gearbox bearings and for several load cases in accordance to current European grid codes. Furthermore, the risk of damage to the gears of the WT during electrical faults are evaluated. In cooperation with the Laboratory for Machine Tools and Production Engineering (WZL) the tooth contact analysis FE-Stirnradkette (STIRAK), based on FE models, will be performed [15]. Knowledge of the damage risk to the gearbox components will enable a determined decision whether countermeasures on the electrical or the mechanical side are necessary for future WTs in order to reduce the WT downtime.

Author Contributions: Conceptualization, methodology and formal analysis, J.R.; investigation, J.R. and F.H.; writing—original draft preparation, J.R.; writing—review and editing, J.R., F.H., T.D., D.B. and G.J.; visualization, J.R.; supervision, D.B. and G.J. All authors have read and agreed to the published version of the manuscript.

Funding: The authors thank the Ministry of Economic Affairs, Innovation, Digitalization and Energy of the State of North Rhine-Westphalia, Germany, for the financial support granted. They also thank their project partners for the support, which contributed to this joint project. 


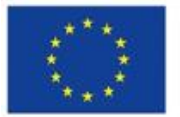

EUROPÄISCHE UNION

Investition in unsere Zukunft Europäischer Fonds

für regionale Entwicklung

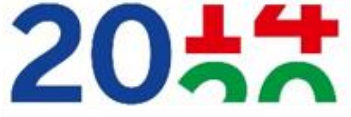

EFRE.NRW

Investitionen in Wachstum und Beschäftigung

Conflicts of Interest: No conflict of interest are declared by the authors.

\section{References}

1. Rohrig, K. Powering the 21st century by wind energy-Options, facts, figures. Appl. Phys. Rev. 2019, 6, 031303. [CrossRef]

2. Erlich, I. Dynamic Behavior of DFIG-Based Wind Turbines during Grid Faults. In Proceedings of the Power Conversion Conference, Nagoya, Japan, 2-5 April 2007.

3. Bartschat, A. Zuverlässige Leistungselektronik für Windenergieanlagen; Final Report; Fraunhofer Verlag: Stuttgart, Germany, 2018.

4. Duda, T. Investigation of dynamic drivetrain behaviour of a wind turbine during a power converter fault. J. Phys. Conf. Ser. 2018, 1037, 52031. [CrossRef]

5. Röder, J. Simulative investigation of the load propagation in a wind turbine drive train during a power converter fault. J. Phys. Conf. Ser. 2020, 1618, 032028. [CrossRef]

6. Sheng, S. Wind Turbine Gearbox Reliability Database, Condition Monitoring, and Operation and Maintenance Research Update. In Proceedings of the Drivetrain Reliability Collaborative Workshop, Golden, CO, USA, 16-17 February 2016.

7. Dao, C. Wind turbine reliability data review and impacts on levelised cost of energy. Wind Energy 2019, 22, 1848-1871. [CrossRef]

8. Röder, J. Simulative investigation of wind turbine gearbox loads during power converter fault. Forsch. Ing. 2021, 85, 251-256. [CrossRef]

9. Van Lier, H. Schädlicher Wälzlagerschlupf. FVA Abschlussbericht 1124, Forschungsvorhaben Nr. 663 I; Forschungsvereinigung Antriebstechnik e.V.: Frankfurt, Germany, 2015.

10. Matzke, D. Full scale system simulation of a $2.7 \mathrm{MW}$ wind turbine on a system test bench. In Proceedings of the Conference for Wind Power Drives, Aachen, Germany, 7-8 March 2017.

11. Matzke, D. Validation of the gearbox load calculation of a wind turbine MBS model. J. Phys. Conf. Ser. 2018, 1037, 62025. [CrossRef]

12. Matzke, D. Validation of MBS modelling methods to calculate bearing and tooth loads in the planetary gear stage of a wind turbine. In Proceedings of the Conference for Wind Power Drives, Aachen, Germany, 12-13 March 2019.

13. Wu, B. Power Conversion and Control of Wind Energy Systems; Wiley: Hoboken, NY, USA, 2011; Volume 29.

14. Kiekbusch, T. Zylinderrollenlagermodul für Simpack, FVA Forschungsvorhaben Nr. 625 II; Final Report 1234; Forschungsvereinigung Antriebstechnik e.V.: Frankfrut, Germany, 2017.

15. Theling, J. Influence of planet carrier misalignments on the operational behaviour of planetary gearboxes. In Proceedings of the 8th WZL Gear Conference, Westminster, CO, USA, 23-24 July 2019. 